\title{
Twig Cutting by the Black Rat, Rattus rattus (Rodentia: Muridae), on the Ogasawara (Bonin) Islands ${ }^{1}$
}

\author{
T. Yabe, ${ }^{2,3,6}$ T. Hashimoto, ${ }^{4}$ M. Takiguchi, ${ }^{5}$ M. Aoki ${ }^{4}$ and M. Fujita ${ }^{4}$
}

\begin{abstract}
Introduced black rats (Rattus rattus) have been reported to damage endemic plants of the Ogasawara Islands by gnawing. This study used seasonal field observations of plants together with analysis of rat stomach contents and age structure to help understand the cause or mechanism of black rat twigcutting activities. Twigs of Ochrosia nakaiana and Hibiscus glaber were found to be cut by black rats on the islands of Nishijima, Anijima, and Mukojima in March and April 2006 and 2007. Fragments of twig tissues in rat feces proved that the rats ate twigs, rather than only gnawing or cutting them. Age compositions of trapped black rats showed that the season of plant damage corresponded with that of low breeding activities of the rats and scarcity of preferred foods (January-March). We assume a link between low breeding activities of the black rats and food shortage, which motivated the rats to consume twig tissues.
\end{abstract}

The BLACK RAT, Rattus rattus, is one of several invasive rodents including the Norway rat, $R$. norvegicus, and the house mouse, Mus musculus, on the Ogasawara (Bonin) Islands (Kawakami 2002), where about 31\% of woody-plant taxa are endemic (Kobayashi and Ono 1987). Among these rodents the black rat is most widely distributed on the islands (Kawakami 2002) and damages vegeta-

\footnotetext{
${ }^{1}$ This study is part of the research project "Studies on eradication of introduced species and the recovery of ecosystems in the Ogasawara Islands (FY2005-2009)" funded by the Global Environment Research Coordination System by Ministry of the Environment, Japan. Manuscript accepted 10 March 2009.

${ }^{2}$ Rat Control Consulting, 1380-6 Fukuda, Yamato, Kanagawa 242-0024, Japan.

3 Tropical Rat Control Committee, c/o Overseas Agricultural Development Association, 8-10-32 Akasaka, Minato-Ku, Tokyo 107-0052, Japan.

${ }^{4}$ Japan Wildlife Research Center, 3-10-10 Shitaya, Taito-Ku, Tokyo 110-8676, Japan.

${ }^{5}$ Japan Wildlife Research Center, Ogasawara Office, Okumura, Chichijima, Ogasawara, Tokyo 100-2101, Japan. .jp).

${ }^{6}$ Corresponding author (e-mail: rccty@js8.so-net.ne
}

Pacific Science (2010), vol. 64, no. 1:93-97

doi: $10.2984 / 64.1 .093$

(C) 2010 by University of Hawai'i Press

All rights reserved tion by eating seeds, fruits, and leaves and by twig cutting and debarking (Kitahara and Sato 2000, Nobushima 2003, Watanabe et al. 2003). Nobushima (2003) and Watanabe et al. (2003) listed a total of 25 tree taxa including 14 endemics such as Hibiscus glaber and Ochrosia nakaiana in Chichijima, Hahajima, and Mukojima that are damaged by twig cutting. This information shows that black rats damage a wide range of endemic trees on the Islands by twig cutting.

Several cases of debarking or suspected debarking by black rats have been reported in Hawai'i, Italy, and Japan (Scowcroft and Sakai 1984, Santini 1987, Yabe 1998, 1999, Kitahara and Sato 2000), but reports on twig cutting by black rats are limited. Watanabe et al. (2003) observed a black rat on a tree and in a cage gnawing twigs of $H$. glaber. However, gnawing is the eponymous characteristic of rodents and is not necessarily linked to eating (Barnett 1975, Timm and Salmon 1988). In this study we examined the mechanism of twig cutting to provide information that might help conserve endemic plants on the Ogasawara Islands.

\section{MATERIALS AND METHODS}

Nishijima $\left(27^{\circ} 07^{\prime} \mathrm{N}, 142^{\circ} 10^{\prime} \mathrm{E}\right)$, Anijima $\left(27^{\circ} 07^{\prime} \mathrm{N}, 142^{\circ} 12^{\prime} \mathrm{E}\right)$, and Mukojima (27 


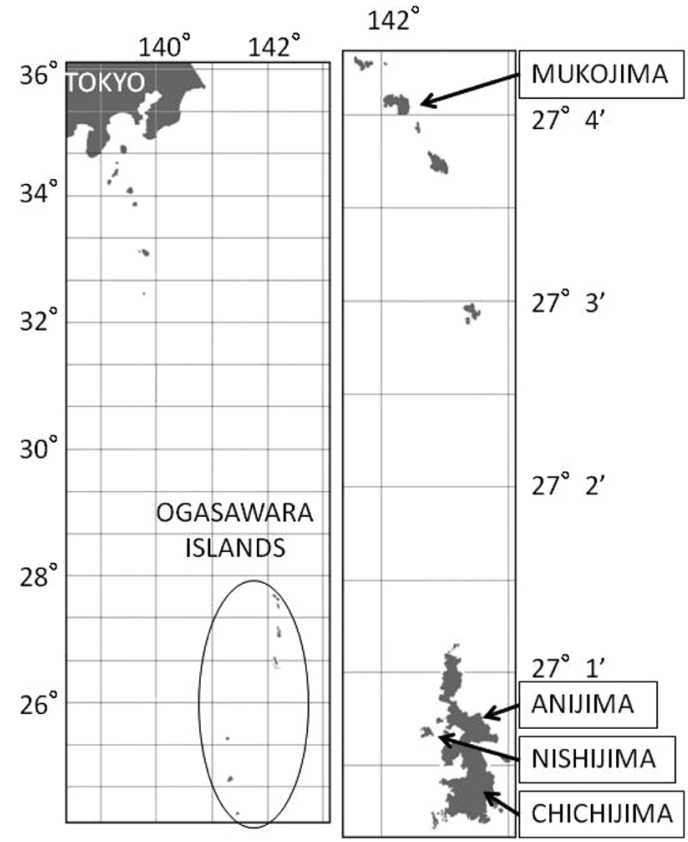

Figure 1. Map of the Ogasawara Islands.

$40^{\prime} \mathrm{N}, 142^{\circ} 08^{\prime} \mathrm{E}$ ) are uninhabited islands of 49 ha, 787 ha, and 257 ha, respectively (Figure 1). They are located in the subtropical climate zone with a mean annual temperature of $23^{\circ} \mathrm{C}$, a mean winter temperature of $18.7^{\circ} \mathrm{C}$, and annual rainfall of 1,280 $\mathrm{mm}$ (data from a meteorological station at Chichijima).

We tried to find signs of twig cutting and collected rats in early July, early October, and early December 2005, and mid-April and late October to early November 2006 in Nishijima; in early December 2006 and mid-March 2007 in Anijima; and in mid-April 2007 in Mukojima. In Nishijima, four trapping sites of about 2,000 $\mathrm{m}^{2}$ each were arranged: (1) natural forest characterized by $H$. glaber, $O$. nakaiana, Terminalia catappa, and Livistona chinensis var. boninensis; (2) Casuarina stricta forest on a hillside; (3) C. stricta forest along a stream; and (4) grassland characterized by Paspalum scrobiculatum. In each site, 30 traps were set at $10 \mathrm{~m}$ intervals for three or four consecutive nights. All these traps were snap traps until December 2005, with five cage traps added in December and cage traps used in April and October-November 2006. Signs of twig cutting were searched for within each site and along the routes between the sites. In Anijima, two trapping sites were arranged in forested areas characterized by Distylium lepidotum or C. stricta. In each site, 50 cage traps were set at $10 \mathrm{~m}$ intervals for three consecutive nights in December 2006 and 50 cage traps and 30 snap traps at $10 \mathrm{~m}$ intervals in March 2007 for four consecutive nights. Signs of twig cutting were searched for around each site. In Mukojima, four trapping sites of about $1,800 \mathrm{~m}^{2}$ each were arranged: (1) grassland predominated by Vitex rotundifolia and P. scrobiculatum, (2) forested area predominated by Terminalia catappa, (3) scrub predominated by Elaeagnus rotundata and Calophyllum inophyllum, and (4) grassland predominated by $P$. scrobiculatum. In each site, 30 cage traps were set for four consecutive nights. Signs of twig cutting were observed around each site and along the routes between these trapping sites.

Collected specimens were sexed and measured by a routine procedure. Stomachs of rats collected with snap traps were removed for examination of their contents under a stereoscopic microscope following the method of Yabe (1979). The percentage volume of food items in each stomach (excluding bait) was estimated, and the mean percentage volume of each food item was calculated across all stomachs examined. Their eyeballs were preserved in $10 \%$ formalin for age determination. Their ages were determined from dried eye-lens weights by Tanikawa's (1993) formula: $x=10^{(Y+44.3) / 43.5}$, where $x$ is predicted age in days and $Y$ is weight of paired lenses in milligrams. The difference in the age compositions between cage-trapped specimens and snap-trapped ones was compared by the Mann-Whitney $U$ test (Yanai 1998). Seasonal changes in breeding activities were estimated from the age compositions.

\section{RESULTS AND DISCUSSION}

We collected a total of 63,84 , and 90 black rats from Nishijima, Anijima, and Mukojima, 
TABLE 1

Age Compositions and Estimated Birth Months of Black Rats Collected in March or April from Nishijima, Anijima, and Mukojima

\begin{tabular}{|c|c|c|c|c|c|c|}
\hline \multirow[b]{2}{*}{ Age (months) } & \multicolumn{2}{|c|}{ Nishijima, April 2006} & \multicolumn{2}{|c|}{ Anijima, March 2007} & \multicolumn{2}{|c|}{ Mukojima, April 2007} \\
\hline & Birth Month & No. of Rats & Birth Month & No. of Rats & Birth Month & No. of Rats \\
\hline$\leq 1$ & Mar. & 0 & Feb. & 0 & Mar. & 4 \\
\hline$\overline{2}$ & Feb. & 0 & Jan. & 0 & Feb. & 0 \\
\hline 3 & Jan. & 2 & Dec. & 6 & Jan. & 0 \\
\hline 4 & Dec. & 4 & Nov. & 15 & Dec. & 1 \\
\hline 5 & Nov. & 4 & Oct. & 12 & Nov. & 3 \\
\hline 6 & Oct. & 1 & Sept. & 4 & Oct. & 5 \\
\hline 7 & Sept. & 2 & Aug. & 5 & Sept. & 9 \\
\hline 8 & Aug. & 1 & July & 3 & Aug. & 11 \\
\hline 9 & July & 2 & June & 1 & July & 15 \\
\hline 10 & June & 0 & May & 2 & June & 9 \\
\hline 11 & May & 2 & Apr. & 3 & May & 6 \\
\hline$\geq 12$ & -Apr. & 4 & - Mar. & 13 & -Apr. & 27 \\
\hline Total & & 22 & & 64 & & 90 \\
\hline
\end{tabular}

respectively, during our survey but found no signs of the other species of rodents. Only 1-16 rats were caught in each trapping period except in April 2006 in Nishijima and in December 2006 in Anijima. These data were excluded from the analysis of age compositions because of the small samples. Table 1 shows the age compositions and estimated birth months of rats collected in March or April from these three islands. All the rats included in the table were collected with cage traps except the rats in Anijima. The age compositions of March 2007 from Anijima were not significantly different between the cagetrapped specimens $(n=46)$ and snap-trapped ones $(n=18)$ at the $1 \%$ level $(Z=1.96<$ $\left.Z_{0.99}=2.33\right)$. Therefore, their age compositions were combined in the table. The age compositions showed that their breeding tended to be active until December but inactive from January to March, with only a few newborns in all the Islands.

We found twig cutting of only $H$. glaber and $O$. nakaiana trees in these islands. Twigs of about $4-5 \mathrm{~mm}$ in diameter of almost all these trees were cut and hung from branches or dropped on the ground in Nishijima in April 2006 (Figure 2A). Some twigs were de- barked and others were excavated to the pith (Figure 2B). In Anijima and Mukojima, twigs of $O$. nakaiana were found to be damaged in March and April 2007, respectively. Clear tooth marks remained on these twigs. Each notch was about $1-1.5 \mathrm{~mm}$ wide, which corresponded to the width of an incisor of black rats (T.Y, unpubl. data). Some of these twigs or leaves died, but some leaves were green. As a result, we confirmed the occurrence of twig cutting in March-April in all the islands but not in the other seasons.

We discovered a pile of twigs under a trunk of H. glaber in April 2006 in Nishijima. Feces were scattered over the pile, and all of them were filled with white fragments of twig tissues (Figure $2 C$ ). Some of these feces contained fragments of insects and a few hairs of rats other than twig tissues. The black rat becomes sexually mature 12-16 weeks after birth, and is a good climber because it was originally an arboreal animal (Meehan 1984). Therefore, it is not surprising that young rats access branch tips and eat twigs. Twig tissues in the feces proved that the black rats ate twigs.

Seeds and fruits are preferred food for black rats in general (Yabe 1979), but their 


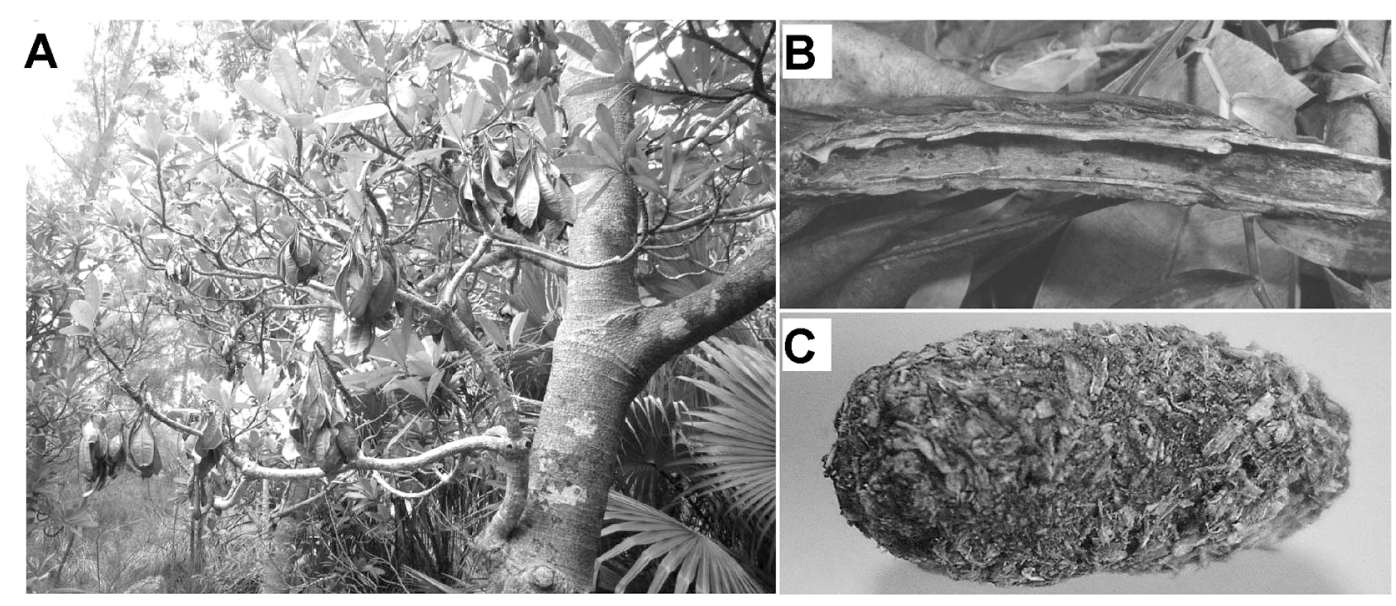

Figure 2. Many leaves of Ochrosia nakaiana hanging from branches $(A)$, twig of $O$. nakaiana excavated to the pith $(B)$, and feces of a black rat filled with fragments of twig tissues $(C)$.

availability changes seasonally. A total of only 14 rats was available for stomach-content analysis between July and December 2005 in Nishijima because snap traps were disturbed by hermit crabs. In the stomach contents of these rats, seeds and fruits, leaves and stems, and insects occupied $84.4 \%, 13.6 \%$, and $2.0 \%$ in volume on the average, respectively. Of them, $P$. scrobiculatum seeds and $C$. stricta seeds were $15.1 \%$ and $14.3 \%$, respectively. We commonly found mature seeds of P. scrobiculatum in grassy places from July to November and piles of fresh cones of C. stricta with gnaw marks of rats in December 2005 and October-November 2006. Therefore, we suppose that these seeds were common in the diets at least between July and December of the rats on Nishijima. In the stomach contents of rats caught in March 2007 in Anijima $(n=13)$, leaves and stems were the major items (75.7\% in volume), and unknown plant materials and insects occupied $22.3 \%$ and $2.0 \%$ on the average, respectively. The crop season of most seeds and fruits finishes in February and such preferred food becomes scarce around March and April on the Ogasawara Islands (Watanabe et al. 2003). As a result, black rats probably need twig tissues to supplement their food around March and April.
Twig cutting in response to scarcity of preferred food is similar to reports of debarking by black rats and other rodents during food shortages. Black rats on an island off southern Japan ate phloem of tankan orange, Citrus tankan, as a supplement because of food shortage after an outbreak of the rats when they were inactive in breeding (Yabe 1998, 1999). Kenward (1989) pointed out that the phloem of beech and sycamore trees has a low energy content, and that there is evidence against any link between debarking and food shortage in gray squirrels. The main season of twig cutting on the Ogasawara Islands (March-April) corresponded with that of low breeding activities (January-March). Watanabe et al. (2003) also found twig cutting of 19 tree taxa mainly in March-April in Chichijima and Mukojima, although they found a few cases in October-November. Therefore, we assume a relationship of low breeding activities of the black rats with food shortage, which motivated the rats to consume twig tissues.

\section{ACKNOWLEDGMENTS}

We thank T. Sugai, K. Shimada, N. Tomioka, J. Maezawa, T. Kaneko, and K. Marcel for their assistance during our field study. 


\section{Literature Cited}

Barnett, S. A. 1975. The rat: A study in behavior. University of Chicago Press, Chicago.

Kawakami, K. 2002. Feral cats and rodents on the Ogasawara (Bonin) Islands. Pages 236-237 in The Ecological Society of Japan, ed. Handbook of alien species in Japan [in Japanese]. Chijinshokan, Tokyo.

Kenward, R. E. 1989. Bark-stripping by grey squirrels in Britain and North America: Why does the damage differ? Pages 144154 in R. J. Putman, ed. Mammals as pests. Chapman and Hall, London.

Kitahara, E., and H. Sato. 2000. Debarking of white popinac Leucaena glauca trees by the black rat Rattus rattus [in Japanese]. For. Pests 49 (7): 13-15.

Kobayashi, S., and M. Ono. 1987. A revised list of vascular plants indigenous and introduced to the Bonin (Ogasawara) and the Volcano (Kazan) Islands. Ogasawara Res. 13: I-VII (text), 1-55 (list of plants).

Meehan, A. P. 1984. Rats and mice: Their biology and control. Rentokil, East Grinstead, United Kingdom.

Nobushima, F. 2003. Damage by eating to native trees by rats on Hahajima [in Japanese]. Annu. Rep. Ogasawara Res. 26:3337.

Santini, L. A. 1987. Rodent debarking activity in urban and natural parks of central Italy: Progress towards integrated control strat- egies. Pages 55-64 in C. G. J. Richards and T. Y. Ku, eds. Control of mammal pests. Taylor \& Francis, London.

Scowcroft, P. G., and H. F. Sakai. 1984. Stripping of Acacia koa bark by rats on Hawaii and Maui. Pac. Sci. 38:80-86.

Tanikawa, T. 1993. An eye-lens weight curve for determining age in black rats, Rattus rattus. J. Mammal. Soc. Jpn. 18:49-51.

Timm, R. M., and T. P. Salmon. 1988. Behavior. Pages 225-235 in I. Prakash, ed. Rodent pest management. CRC Press, Boca Raton, Florida.

Watanabe, K., H. Kato, and M. Wakabayashi. 2003. Damage by eating to native plants by black rats Rattus rattus on the Ogasawara (Bonin) Islands [in Japanese]. Annu. Rep. Ogasawara Res. 26:13-31.

Yabe, T. 1979. The relation of food habits to the ecological distributions of the Norway rat (Rattus norvegicus) and the roof rat $(R$. rattus). Jpn. J. Ecol. 29:235-244.

- 1998. Bark-stripping of tankan orange, Citrus tankan, by the roof rat, Rattus rattus, on Amami Oshima Island, southern Japan. Mammal Stud. 23:123-127.

. 1999. Outbreak of the black rat, Rattus rattus: The main cause of barkstripping of tankan orange [in Japanese]. For. Prot. 269:7-8.

Yanai, H. 1998. 4-steps Excel statistics (with Statcel add-in software) [in Japanese]. OMS, Saitama, Japan. 
